\title{
Dialectical Shifts Underlying Arguments from Consequences
}

\section{Douglas WaLton}

\author{
Centre for Research in Reasoning, Argumentation \& Rhetoric \\ Department of Philosophy \\ University of Windsor \\ Windsor, $O N$ \\ Canada N9B 3P4
}

dwalton@uwindsor.ca

\begin{abstract}
Eight structural criteria are developed as part of a dialogical method by testing them against seven examples of arguments from negative consequences. The aim is to provide a method for evaluating the arguments in the examples as fallacious or not. It is shown that any method that can be satisfactorily used to evaluate such examples needs to be based on two techniques. The first is careful application of argumentation underlying shifts from one type of dialog to another schemes. The second is consideration of contextual factors concerning.
\end{abstract}

Résumé: On développe huit critères dans une approche dialogique pour déterminer si des arguments fondés sur des conséquences négatives sont fallacieux. On montre que n'importe quelle méthode qu'on peut employer pour évaluer de façon satisfaisante ces types d'arguments doit reposer sur deux techniques: une application soignée des schèmes argumentatifs; et l'examen de facteurs contextuels concernant des changements sous-jacents lorsqu'on passe d'un type de dialogue à un autre

Keywords: ad consequentiam fallacy; ad baculum fallacy; types of dialog; practical reasoning; value-based reasoning; dialog relevance; persuasion dialog; deliberation.

The task undertaken by this paper is to extend the dialog methodology of (Walton and Krabbe, 1995) to get help with attacking the problem of using the notion of a dialectical shift more effectively as a tool to help us to evaluate problematic cases of arguments from negative consequences, especially those associated with certain informal fallacies. Argument from negative consequences has a distinctive argumentation scheme, and so does argument from threat, a subspecies of argument from negative consequences famously associated with the ad baculum fallacy. But based on seven key examples, it is shown how the schemes for these two types of argumentation are insufficient as tools to enable us to fairly judge, in any given case, whether such an argument is fallacious or not. The schemes required to analyze the examples are presented in section 1. The examples are used to show that argument from

(C) Douglas Walton. Informal Logic, Vol. 29, No.1, pp. 54-83. 
negative consequences, including argument from threat, are sometimes quite reasonable, but that, in some instances, both can be used as deceptive sophistical strategies. ${ }^{1}$ The problems are (a) to put in place normative structures that can be used to analyze and evaluate these arguments, and (b) to use this methodology as a basis for determining whether a given instance is fallacious or not. It is shown that this procedure needs to be carried out at two levels. At an inferential level, it requires employment of argumentation schemes, but also at a dialectical level it needs to take dialectical shifts into account (transitions as a chain of argumentation moves from one conversational context to another).

It is shown that once these tricky types of argument are clearly defined using argumentation schemes that exhibit the forms of reasoning on which each is based, each individual instance can be analyzed and evaluated using a retrospective model that takes dialectical shifts into account. A retrospective analysis is then applied, using formal dialectical models of rational argumentation (Wells and Reed, 2006) that have rules that specify when a progression over a dialectical shift is legal or not. This task is taken to be dialectical, or logical in nature, but it does suggest another problem that is rhetorical in nature. This other problem is that of explaining why these arguments are often so persuasive even when they are fallacious. Why is it that they are so rhetorically powerful in everyday conversational argumentation, and commonly effective as widely exploited rhetorical techniques of persuasion used in media argumentation? No direct attempt is made to solve this rhetorical problem, but at the end of the paper some dialectical resources for approaching it are suggested.

\section{Argumentation schemes}

The argumentation scheme for argument from consequences represents a very common form of argumentation. In argument from positive consequences, a particular policy or course of action is recommended by citing positive consequences of carrying it out. Argument from negative consequences cites negative consequences of carrying the policy out, and uses that as a reason to argue against carrying it out. Such arguments are quite often reasonable. For example, your physician might recommend against your nutritional habits by arguing, "Eating too much salt has the consequence of raising blood pressure; raising blood pressure is a bad consequence for you; therefore you should not eat too much salt." Argument from consequences is also often used in ethical and political deliberations on what course of action to take, given a choice. Aristotle clearly recognized how this form of argument can be used by both sides in a disputation in Rhetorica (1399a14 - 1399a15). ${ }^{2}$

\footnotetext{
${ }^{1}$ The thesis that fear and threat appeal arguments are often reasonable, but are fallacious in some instances of their use, has been supported through the analysis of both kinds of argument in (Walton, 2000).

${ }^{2}$ The quotation is from the Loeb Classical Library Edition (311).
} 
. . .since in most human affairs the same thing is accompanied by some bad or good result, another topic consists in employing the consequences to exhort or dissuade, accuse or defend, praise or blame. For instance, education is attended by the evil of being envied, and by the good of being wise; therefore we should not be educated, for we should avoid being envied; nay, rather, we should be educated, for we should be wise.

A topic is a defeasible form of argument of a kind that is nowadays called an argumentation scheme. It is not hard to appreciate how common argumentation from consequences is, and how it is often used as a reasonable form of argumentation. Still, an inherently reasonable form of argument can sometimes be used as a sophistical tactic to try to get the best of an opponent unfairly in disputation.

Two argumentation schemes representing the two forms of argumentation from consequences have been put forward in (Walton, 1996, p. 75). The scheme for argument from positive consequences takes the following form.

Argumentation Scheme for Argument from Positive Consequences

PREMISE: If $A$ is brought about, good consequences will plausibly occur.

CONCLUSION: $A$ should be brought about.

The scheme for argument from negative consequences takes the following form.

\section{Argumentation Scheme for Argument from Negative Consequences}

PREMISE: If $A$ is brought about, bad consequences will plausibly occur.

CONCLUSION: $A$ should not be brought about.

According to (Walton, 1996, pp. 76-77), three critical questions match the scheme.

CQ1. How strong is the probability or plausibility that these cited consequences will (may, might, must) occur?

CQ2. What evidence, if any, supported the claim that these consequences will (may, might, must) occur if $A$ is brought about?

CQ3. Are there consequences of the opposite value that ought to be taken into account?

The argument has a presumptive status, once the positive or negative consequences are cited as reasons to support the proposed course of action. But the argument is cast into doubt if there is a failure to answer any of these 
critical questions adequately, once they have been asked. So conceived, argument from consequences can be strong in some cases, weak in others. It can be weak if it fails to answer appropriate critical questions that have been or might be asked in a dialogue.

Argument from consequences is closely related to another argumentation scheme called practical reasoning.

\section{Scheme for Practical Reasoning}

MAJOR I have a goal $G$.

PREMISE:

MINOR

Carrying out this action $A$ is a means to realize $G$.

PREMISE:

CONCLUSION: Therefore, I ought (practically speaking) to carry out this action $A$.

\section{Critical Questions}

$\mathrm{CQ}_{1}$ : What other goals do I have that should be considered that might conflict with $G$ ?

$\mathrm{CQ}_{2}$ : What alternative actions to my bringing about $A$ that would also bring about $G$ should be considered?

$\mathrm{CQ}_{3}$ : Among bringing about $A$ and these alternative actions, which is arguably the most efficient?

$\mathrm{CQ}_{4}$ : What grounds are there for arguing that it is practically possible for me to bring about $A$ ?

$\mathrm{CQ}_{5}$ : What consequences of my bringing about $A$ should also be taken into account?

It can be seen from the last critical question how argument from consequences is related to practical reasoning. There is also another argumentation scheme that is closely related to argument from consequences.

\section{Schemes for Arguments from Values}

Variant 1: Argument from Positive Value

PREMISE 1: $\quad$ Value $V$ is positive as judged by agent $A$ (judgment value).

PREMISE 2: $\quad$ The fact that value $V$ is positive affects the interpretation and therefore the evaluation of goal $G$ of agent $A$ (If value $V$ is good, it supports commitment to goal $G$ ).

CONCLUSION: $V$ is a reason for retaining commitment to goal $G$.

Variant 2: Argument from Negative Value.

Premise 1: $\quad$ Value $V$ is negative as judged by agent $A$ (judgment value). 
PREMISE 2: $\quad$ The fact that value $V$ is negative affects the interpretation and therefore the evaluation of goal $G$ of agent $A$ (If value $V$ is bad, it goes against commitment to goal $G$ ).

CONCLUSION: $V$ is a reason for retracting commitment to goal $G$.

How value-based argumentation works in persuasion dialogue and relates to practical reasoning is well explained by (Bench-Capon, 2003) and (Atkinson, Bench-Capon and McBurney, 2006). Argument from values is combined with practical reasoning in the type of argumentation called value-based practical reasoning (Bench-Capon, 2003; Atkinson, Bench-Capon and McBurney, 2006). A scheme for value-based practical reasoning combining these elements is formulated below (Walton, Reed and Macagno, 2008, chapter 9).

\section{Scheme for Value-based Practical Reasoning}

PREMISE 1: $\quad$ I have a goal $G$.

PREMISE 2: $\quad G$ is supported by my set of values, $V$.

PREMISE 3: $\quad$ Bringing about $A$ is a means for me to bring about $G$.

CONCLUSION: Therefore, I should (practically ought to) bring about $A$.

Thus it can be seen that there is a cluster of argumentation schemes combining practical reasoning with argument from consequences and argument from values. Precisely how the schemes are related to each other, and how they should be classified as forming an organized cluster of schemes, are problems for future research

There is also another group of argumentation schemes that forms part of this cluster. These schemes have to do with the making of a threat within an argument from consequences, and form part of the structure of the kind of argumentation traditionally classified under the heading of argumentum ad baculum in logic. The essential condition that differentiates the threat type of ad baculum argument from a regular argument from consequences that is not an ad baculum argument requires that a special premise must be present. This premise is the making of a threat by the proponent. In the speech act of making a threat, the speaker declares the intention of carrying out a designated action not wanted by the hearer, unless the hearer carries out another designated action (Nicoloff, 1989; Guerini and Castelfranchi, 2006). Following this view, making a threat can be defined as a speech act (type of move) in a dialog exchange. This speech act that takes the following form: I (the proponent) am making a commitment to see to it that the negative consequences for you (the respondent) come about, unless you bring about the action I request. This expression of commitment by the proponent is an essential characteristic of the appeal to threat type of ad baculum argument. If the proponent only makes a warning to the respondent in a case, but not a threat, the argument should be classified under the category of argument from negative consequences, but not under the category of the threat appeal subtype. For the speech act to really be the making of a threat, the proponent must convey his commitment to seeing to it that the negative consequences occur. 
Accordingly, argument from threat has the following argumentation scheme (Walton, Reed and Macagno, 2008, 333), where $A$ and $B$ represent outcomes that can be brought about by an agent.

\section{Scheme for Argument from Threat}

PREMISE 1: $\quad$ If you bring about $A$, some cited bad consequences, $B$, will follow.

PREMISE 2: $\quad$ I am in position to bring about $B$.

PREMISE 3: $\quad$ I hereby assert that in fact I will see to it that $B$ occurs if you bring about $A$.

CONCLUSION: Therefore you had better not bring about $A$.

It is clear from the discussion above that argument from threat should be classified as a subspecies of argument from negative consequences. It should also be clear that although such an argument should be seen as defeasible and subject to critical questioning, it is not generally fallacious, but only fallacious in certain instances under certain conditions. One such condition is where there has been a dialectical shift of a certain sort from one context of dialog to another.

\section{Dialectical shifts}

In the dialog typology of Walton and Krabbe (1995), there are six primary types of dialog: information-seeking dialog, inquiry dialog, persuasion dialog, negotiation dialog, deliberation dialog and eristic dialog. These dialogs are technical artifacts called normative models, meaning that they do not necessarily correspond exactly to real instances of persuasion or negotiation, etc. that may occur in a real conversational exchange. Each model of dialog is defined by its initial situation, the participants' individual goals, and the collective goal of the dialog as a whole.

Dialectical shifts were analyzed in (Walton and Krabbe, 1995, pp. 100116). In a common kind of example, there is a shift from deliberation dialogue to an information-seeking type of dialogue. For example suppose there is a debate in a legislative assembly on whether to pass a bill to install a new dam. Before those in the assembly will vote on this question, they will want to find out many facts about how the dam will be constructed, what its ecological consequences will be, and what it will cost to install it. In order to examine these questions they will call in experts, like experts in engineering and ecology, and they might also interview accountants who have calculated the cost of the dam, and persons whose property might be affected by the dam. When this happens there has been a shift from a deliberation dialog on whether it would be a good idea to install such a dam to an information-seeking dialog about matters like what the consequences of installing the dam would be and what its costs would be. In this kind of case the dialectical shift is classified as 
an embedding (Walton and Krabbe, 1995, 102), meaning that the goal of the first dialogue, the deliberation, is supported by the advent of the second dialog, the information-seeking interval.

However, some dialectical shifts are classified as illicit, meaning that the advent of the second dialogue blocks or interferes with the progress of the first (Walton and Krabbe, 1995, p. 107). To make this analysis precise, two theoretical tasks have to be carried out. First, we need to have a model of deliberation as a type of dialog, so that it can be distinguished form other types of dialog, like persuasion dialog and negotiation. Second, we need to use these models of dialog to get more precise idea of when such shifts occur to help us judge whether they are licit or illicit.

How a dialectical shift works in the case of a threat appeal argument can sometimes be explained in the common kind of case in which there is a shift from a critical discussion to a negotiation type of dialog. The making of a threat to influence the other side is in many cases a reasonable kind of argument strategy in negotiation. Threats are risky in negotiation, and can sometimes be inappropriate, but generally they are regarded as a reasonable sort of argumentation in negotiation. For example in union management negotiations, threats of various kinds are commonly made by both sides, and are part of the central fabric of the argumentation used in such cases. However, threats are irrelevant and obstructive in a critical discussion. If an argument starts out to be a critical discussion, but then shifts to a negotiation dialogue, the ad baculum argument used during the sequence of argumentation could be fallacious.

Wells and Reed (2006) constructed two formal dialectical systems to model dialectical shifts from persuasion dialog to negotiation dialog based on specifying a unified architecture for argumentation. When two participants are engaged in a persuasion dialog, and they want to shift to a new sub-dialog, they must make a request for the shift to be legal (licit), and several requirements need to be met. When these requirements are met by a shift initiated by one party, the other party has the option of continuing in the current dialogue or agreeing to carry over into the shift. Wells and Reed have designed rules for both the persuasion dialog and the negotiation dialog specifying termination rules for both. Their rules are designed to allow for a clean progression, as they call it, from one type of dialog to another. For example, one party could take advantage of the opportunity to shift to a negotiation dialog by making the appropriate move, but the respondent could make a counteroffer. Such metadialog negotiations can help the two parties reach agreement, because even though they have run out of arguments in the persuasion dialogue, still they might reach agreement on how to proceed further by making a shift. There seems to be no reason why their analysis cannot be extended to other kinds of shifts, like the shift from a persuasion dialog to a deliberation dialog. However, we need to have a clear account of the characteristics of both types of dialog.

In a persuasion dialog, one participant puts forward a thesis to be proved, and the other puts forward an opposed thesis, or else expresses doubt about the first party's thesis. As in all types of dialog, there are three main stages, the opening stage, the argumentation stage and closing stage. The purpose of a 
persuasion dialog is to resolve this initial conflict of the opening stage by putting forward arguments on both sides at the argumentation stage (Prakken, 2006). The overarching principle of burden of proof, called the burden of persuasion, the requirement that he who asserts must prove, is set at the opening stage. Meeting the burden of persuasion is determined by three factors: (1) what strength of argument is needed to win the dialog for a participant at the closing stage (standard of proof), (2) which side bears the so-called burden for producing such an argument, and (3) what kind of argument is required for this purpose. 'Winning' means producing an argument that is stronger enough than the opponent's argument to lift the burden of persuasion set at the opening stage. In contrast to the burden of persuasion that applies over the whole dialog from opening to closing, there is also the evidential burden (called the burden of production in law) that applies during the argumentation stage when a particular claim is made or a particular argument is put forward. Both burden of persuasion and evidential burden are burdens of proof.

In the formal model of deliberation dialog presented by McBurney, Hitchcock and Parsons (2007, 100), a deliberation dialog consists of an opening stage, a closing stage, and six other stages making up the argumentation stage.

Open: In this stage a governing question is raised about what is to be done. A governing question, like 'Where shall we go for dinner this evening?', is a question that expresses a need for action in a given set of circumstances.

Inform: This stage includes discussion of desirable goals, constraints on possible actions that may be considered, evaluation of proposals, and consideration of relevant facts.

Propose: Proposals cite possible action-options relevant to the governing question

Consider: this stage concerns commenting on proposals from various perspectives.

Revise: goals, constraints, perspectives, and action-options can be revised in light of comments presented and information gathering as well as factchecking.

Recommend: an option for action can be recommended for acceptance or nonacceptance by each participant.

Confirm: to participant can confirm acceptance of the recommended option, and all participants must do so before the dialog terminates.

Close: The termination of the dialog.

An important property of deliberation dialog is that an action-option that is optimal for the group considered as a whole may not be optimal from the perspective of an individual participant (McBurney, Hitchcock and Parsons, 2007, 98). In a deliberation dialog, a participant must be willing to share both his/her preferences and also information with the other participants. The initial situation of deliberation is the need for action arising out of a choice between 
two or more alternative courses of action that are possible in a given situation. The ultimate goal of deliberation dialog is for the participants to collectively decide on what is the best available course of action for them to take.

Both deliberation and persuasion dialogs can be about actions, and therefore we have to try to draw a bright line more carefully between these two types of dialog. Deliberation is not centrally an attempt by one participant to persuade another to become committed to a particular proposal, although it is quite common for there to be a shift to persuasion dialog as reasons for or against a proposed action are supported were criticized. There appears to be no burden of proof in a deliberation dialog, comparable to the central notion of burden of proof in persuasion dialog, but this matter has so far not been studied. Argumentation in deliberation is primarily a matter of supporting one's own proposal with reasons to accept it, and critiquing the other party's proposal. Also, one's proposal may need to be abandoned if the reasons given against it are strong enough to show that the opposed proposal is better to solve the problem posed at the opening stage. Deliberation dialog is different from negotiation dialog, which deals with competing interests, because the participants evaluate proposed courses of action according to standards that may be contrary to their personal interests.

\section{Problematic examples of arguments from negative consequences}

Argument from consequences (argumentum ad consequentiam) has been cited as a fallacy in some modern logic textbooks. Rescher (1964, p. 82) warned that "logically speaking", it can be "entirely irrelevant that certain undesirable consequences might derive from the rejection of a thesis, or certain benefits accrue from its acceptance". He (1964, p. 82) cited the following example, which could be called the classic case, because it illustrates the error very well to logic students.

\section{The Mexican War Example}

The United States had justice on its side in waging the Mexican war of 1848. To question this is unpatriotic, and would give comfort to our enemies by promoting the cause of defeatism.

In this instance, argument from consequences is classified as a fallacy on the ground that is not relevant to the issue supposedly being discussed. The issue was supposedly the historical/ethical conflict of opinions on which side was in the right in the Mexican war of 1848. It seems that there has been a shift to a different issue when one side argues from negative consequences by saying that questioning that the U.S. was in the right would promote defeatism.

The Mexican-American War, called the Mexican War in the United States and the United States Invasion in Mexico, was an armed military conflict between the United States and Mexico from 1846 to 1848. The war arose because Mexico did not recognize the secession of Texas when the U.S. 
annexed Texas in 1845. The Mexican government permitted a few hundred American families to settle the area, and English speaking settlers formed a majority in Texas. Texans became unhappy with the Mexican government, and this situation led to the conflict.

The Mexican war argument would seem to be an example of a dialectical shift that should be classified as illicit, given the judgment that the prudential deliberation about whether questioning whether the U.S. had justice on its side would give comfort to our enemies is not relevant to resolving the issue of which side had justice on its side in the Mexican war. Rescher $(1964,82)$ classified this case as an instance of a fallacy of relevance. On this evaluation of the fallacy of relevance, the shift to this prudential issue is merely a distraction that interferes with the progress of the original critical discussion by distracting the audience away by introducing another issue that may be more pressing, but is not useful to resolve the original dispute. It may indeed have been true that saying so would have bad consequences for the national interest. Still, this assertion is not relevant to the issue of which side was in the right. However, to show exactly why not is tricky. We have to have some criterion of relevance, and we have to show precisely why the argument in this case violated that criterion.

Argument from consequences is closely associated with other types of arguments traditionally recognized as informal fallacies.

\section{The Riots Example}

If the defendant is acquitted, there will be riots. Therefore, he should be found guilty.

It may be true that there will be riots if the defendant is acquitted, but if there is to be fair trial, it should not follow that the defendant should be found guilty. In this case it is easy to recognize the fallacy right away, because of what we know about fair trials. The consequence of riots is not evidence of the kind required in a fair trial. Spelling out exactly which requirement of a fair trial (notions of relevance, admissibility and evidence) is involved, would not be a trivial job, however, for an argumentation theorist.

Another example does not seem fallacious at all when you first look at it.

\section{The Drinking Example}

You should stop drinking unless you want to die young like your father.

This example seems reasonable enough as a piece of advice, but it depends on the circumstances. The parallel between the case of the respondent and his father may be open to challenge. As an argument from negative consequences it might be reasonable or not. It doesn't seem to be fallacious, perhaps just weak or questionable. 
In short, there are problems in evaluating all three examples to judge whether they are reasonable or fallacious. A specific problem with the first two examples is that there seems to be an underling shift from an issue about whether a proposition is true or false, based on the evidence, to a prudential issue about actions. In the drinking example, the issue seems to be prudential, from all we can judge, and so there seems not to be such a shift. Note that the riots example in particular, but perhaps the other two examples well in lesser degree, may invoke the traditional fallacy category of argumentum ad baculum, since it may suggest something threatening to the respondent. Certainly it may act as a fear appeal.

Other kinds of arguments associated with fallacies, like the slippery slope argument, are sometimes based on argumentation from negative consequences. Many of the examples of the fallacious argumentum ad baculum found in logic textbooks involve the use of a threat of negative consequences. The logic textbooks tend to define argumentum ad baculum as the use of force or a threat by one party in a dispute, to try to get the other party to accept an argument he is advocating (Walton, 2000, chapter 2). Many accounts, however, have a more inclusive treatment that includes arguments that appeal to fear, even if no threat is made. In this paper, we are not directly concerned with use of force (say, by taping your opponent's mouth shut) or with fear appeals. The type of ad baculum argument we are concerned with concerns the use of a threat. The scheme for this form of argument is that of argument from negative consequences, along with the additional premise that the speaker makes a threat to the hearer. When the proponent makes a threat in this type of argument, she is not only telling the respondent that the bad state of affairs $B$ will or may happen, unless he brings about $A$. This premise adds a personal factor to the effect that the proponent is declaring that she will bring about the event $B$, unless the respondent takes the proposed action with respect to $A$. The fear appeal argument is not based on a threat.

It is known that whether ad baculum arguments are fallacious depends on the context of the dialog in the case at issue (Walton, 2000). In negotiation dialog, threats are accepted (within limits) as normal argumentation strategies, whereas in a critical discussion, threats are not relevant. In a critical discussion, participants are not supposed to prevent the other party from advocating his viewpoint or critically questioning the other's viewpoint (van Eemeren and Grootendorst, 2004, 190). The making of a threat as an argument could go

against this rule of a critical discussion. The making of a threat could also be irrelevant by violating the relevance rule of a critical discussion (192).

\section{The Free Will Example}

A professor and a student are discussing the issue of free will versus determinism in a philosophy seminar, and the professor says, "You had better stop advocating that argument against free will or I'll give you a failing grade in this course!" 
It would be evident to the participants in the class that this argument is inappropriate. The shift from the critical discussion to some sort of prudential act of warning or threat is a clear indicator that the professor has committed an ad baculum fallacy. It is an argument from negative consequences, and prudentially, it may be wise for the student to act in accord with it, but it is not relevant to the discussion supposedly taking place.

Ad baculum arguments that are based on the use of a threat often take the form of an indirect speech act. The following example is a classic case.

\section{The Firebombing Example}

The last person who didn't buy protection from our association was the victim of an unfortunate accident. Therefore, it would be prudent for you to buy our protection insurance in order to prevent such unfortunate consequences of not having it.

This example looks on the surface like a warning, as in the drinking example. The indirect threat allows for plausible deniability for the proponent of the threat. Later the "insurance salesman" can say it was just a warning, even if, at the time, respondent, at the time the threat was made, would recognize it as a threat. ${ }^{3}$ The indirect threat involves the use of a strategy of deception.

Consider another example made up to represent a common type of case.

\section{The Jury Intimidation Example}

In a case of jury intimidation, a jury member realizes quite well that a motorcycle gang's threat to kill him is irrelevant as legal evidence that should be considered in the trial. But he asks to be taken off the jury because he fears for his life.

In this example, the threat used to intimidate the jury member is direct rather than indirect, assuming there was no attempt to disguise it as a warning. Still, it is credible and effective because of who has made it, and because of the respondent's normal commitment to his own interests and safety. The logic texts would probably classify the argumentation in the example as fitting under the heading of the argumentum ad baculum, and as such, it would no doubt be taken to commit the ad baculum fallacy. It is similar to the riots example in certain respects, but also introduces some new factors that will be considered in section 5.

In his book, The Enemy at Home, right-leaning author Dinesh D'Sousa employed a novel and interesting argument against left-leaning politicians, celebrities and activists to blame recent terrorist attacks by Islamic

\footnotetext{
${ }^{3}$ Many examples of indirect threat arguments of this sort are studied in (Walton, 2000).
} 
fundamentalists. The description of the argument presented in the example is a very brief summary. ${ }^{4}$

\section{The Domestic Insurgency Example}

D'Sousa denounced America as having sunk into decadent moral values, he argued that religious fundamentalists, with some justification, judged America as the worst civilization for decadent values. Examples of decadent actions he cited include widespread use of intoxicants, gambling, and fornication. He argued that the attempts to promote gender equality in the developing world can be seen as promoting values considered disgusting and deviant by traditional cultures. He named more that a hundred left-leaning politicians, celebrities and activists whose actions, he argued, were responsible for the causing the hatred of the terrorists because of their attempts to promote these decadent moral values and impose them on the rest of the world. He did not accusing them of being terrorists themselves, or of even of actively working to promote the interests, of the terrorists. However, he argued that because of the consequences of their actions, they were taking part in a "domestic insurgency" that was, in effect, "working in tandem" with Osama bin Laden to defeat George W. Bush.

This example of the use of argument from negative consequences is highly controversial, and no doubt many of those attacked by it are antagonized by it. D'Sousa cited many activities to promote their "decadent" views by activists, intellectuals and celebrities that, he alleged, had negative consequences for America. Can we conclude that the argument in the domestic insurgency example is a fallacious instance of argumentation from negative consequences? We return to a discussion of this question in section 5 .

\section{Analysis of the Mexican War example}

We now return to a discussion of each of the examples in turn, beginning with the Mexican war example. In each case should begin by trying to see which argumentation scheme fits the argument in the example. In order to do this, we have to analyze the argument in the example and identify its premises and conclusion. An analysis of the structure of the Mexican war argument is shown in Figure 1.

\footnotetext{
${ }^{4}$ A review of the book presents a summary on which some details of the example are based: Jerry Adler, 'America's Most Wanted' (review of The Enemy at Home) Newsweek, Feb. 5, 2007, p. 46.
} 


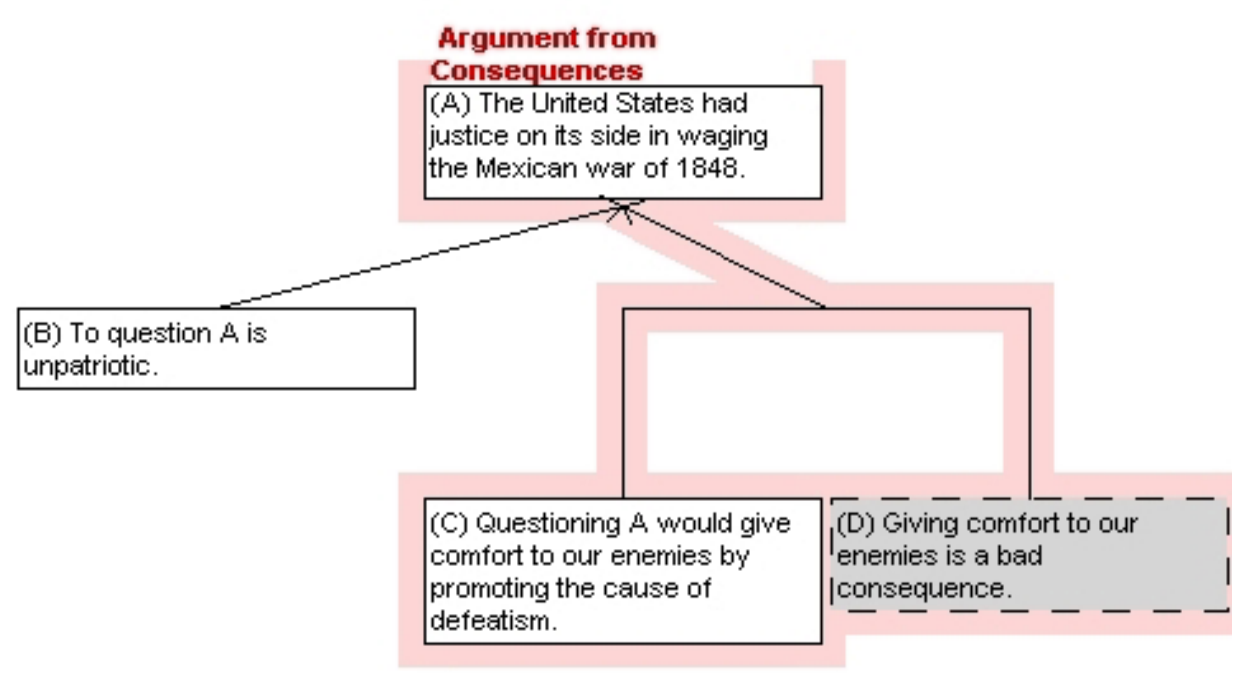

Figure 1: First Argument Diagram of the Mexican War Example

In the diagram in Figure 1, the missing premise D has been inserted. It is shown in a darkened box, indicating that it has been added as an implicit premise. The argumentation scheme (argument from consequences) that links premises $\mathrm{C}$ and $\mathrm{D}$ to conclusion $\mathrm{A}$ has been represented on the diagram. ${ }^{5}$

What is tricky about the argument can be approached by looking at Figure 1. Figure 1 represents the routine way that the argument in the Mexican war example should be represented by an argument diagram. But when the argument is represented in this way, it seems blatantly wrong, because the arguments composed of $\mathrm{B}$ and $\mathrm{C} \& \mathrm{D}$ do not support the truth of the conclusion A. But what has gone wrong? What these two arguments do support is another conclusion A+: 'You (the respondent) should not question (in public) the proposition that the United States had justice on its side in waging the Mexican war of 1848'. This way of analyzing the argument is represented in the argument diagram in Figure 2.

\footnotetext{
${ }^{5}$ In this instance it is argument from negative consequences.
} 


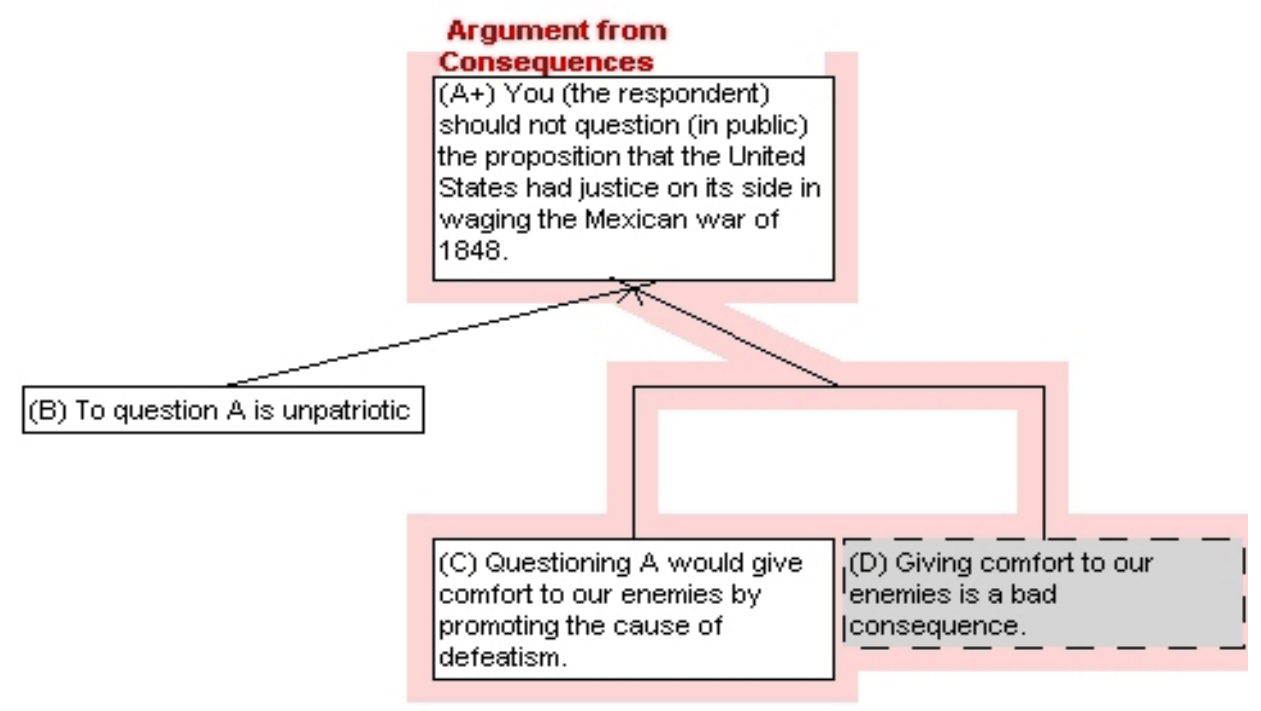

Figure 2: Second Argument Diagram of the Mexican War Example

Looking at the argument as shown in Figure 2, it seems reasonable. The two arguments can correctly be seen as offering reasons to support the conclusion $(\mathrm{A}+)$.

Comparing the two argument diagrams, we begin to get some inkling of what has gone wrong. The argument could be classified as an instance of the fallacy of arguing to the wrong conclusion. The fallacy can be diagnosed using this triad.

Remark 1: $\mathrm{B}$ and $\mathrm{C} \& \mathrm{D}$ do not give reasons to support acceptance of conclusion A.

Remark 2: $\mathrm{B}$ and $\mathrm{C} \& \mathrm{D}$ do give reasons to support acceptance of conclusion $\mathrm{A}+$.

Remark 3: It is easy to confuse A with A+.

Remark 3 is a plausible statement because the difference between $\mathrm{A}$ and $\mathrm{A}+$ is subtle. It is the difference between saying that some statement is true (or not), as supported by evidence, and saying that saying this statement is true (or not) is commendable (or not). A is a statement about something, while $\mathrm{A}+$ is a statement about talking about A.

What could be called the fallacy of arguing to the wrong conclusion is an argument fitting the following pattern (Walton, 2004, 35): the arguer is supposed to prove conclusion A, but he puts forward an argument for conclusion $\mathrm{A}+$, a proposition that looks like (or appears to be the same as) A. Aristotle seemed to have something like this fallacy in mind when he made the following remark about what he called the fallacy of misconception of refutation: "When the argument stated is a demonstration [apodeixis] of something, if it's something other than that leading to the conclusion, it will 
not be a syllogism about that thing."(Topica 162a13-162a16; quoted from the translation in Walton, 2004, 35). Seen in this way, the fallacy in the Mexican war example can be diagnosed as a failure of relevance of a specific kind, namely the fallacy of arguing for the wrong conclusion. But why would anyone be fooled by such an error of arguing for the wrong conclusion? More must be involved than the simple error revealed by the juxtaposition of the inferential structures shown in Figures 1 and 2.

What gives the fallacious argument its aura of plausibility is the melding together of the reasonable argument from consequences shown in Figure 2 with the patently unreasonable argument shown in Figure 1. What could lead a respondent to blend these arguments together and take them to be the same? Why is the argument so highly deceptive because of this concealed blending? How could we train students of critical thinking to recognize such a deception that conceals the shift from the one argument to the other one? How do such arguments have such a powerful persuasive effect as rhetorical strategies of strategic maneuvering (van Eemeren and Houtlosser, 2000)? It will now be argued, by proceeding to a second level of analysis, that the reason for this deceptiveness is a failure of relevance concealed by an implicit contextual shift .

As noted, Rescher $(1964,82)$ categorized the fallacy as a failure of relevance. This diagnosis calls into question why the argument should be considered not relevant. This suggests examining the context of dialog in which the argument was used. This argument could be relevant if the dialog were that of a deliberation on how to act in a given situation. We see from the wording of the case that "enemies" are involved, so let us imagine that the situation is one in which there is some current conflict or war. In this scenario, giving comfort to enemies would be a negative consequence, and might even lead to loss of life for the soldiers on our side. This wording suggests a deliberation on how to act prudently. But suppose on the other hand the context of dialog is that of a persuasion dialog, of the kind one might have in a history class or an ethical discussion about which side was in the right in the Mexican war. Here the very same argument could be judged to be irrelevant, because the original discussion was supposed to be about the ethical/historical issue of which side "had justice on its side" in waging the war. Relevant arguments in such a persuasion dialog would be historical facts like who started the conflict, what were the territorial claims of each side, and so forth. Only these kinds of argument can fulfill the original burden of persuasion.

In order to back up the claim that the argument in the example commits a fallacy of irrelevance because the discussion was not originally supposed to be a deliberation dialog, it can be hypothesized there has been a shift from one type of dialog to another inherent in the argumentation in the example. The original dialog was supposedly, from all we can tell from the information given in the example, a persuasion dialog on which side had justice on its side in waging the Mexican war of 1848. The goal of such a discussion is to resolve this conflict of opinions by examining the rational arguments on both sides. However, there was a kind of shift made when the premises were brought 
forward that to question whether the United States had justice on its side is unpatriotic, and that doing so would give comfort to our enemies by promoting the cause of defeatism. What needs to be carefully observed is that these two statements may very well be true, and the analysis in the argument diagram in Figure 2 could be judged to be a reasonable argument. It is based on an argumentation scheme that has true premises. In this format, the argument would reasonably provide a prudential argument against questioning whether the United States had justice on its side by citing negative consequences of such questioning, namely that it would give comfort to our enemies by promoting the cause of defeatism. This prudential argument only becomes irrelevant and fallacious when expressed in its original form in Figure 1. Thus there are two levels of analysis that need to be considered together-an inferential level and a dialectical one.

This bi-level analysis depends on how the notion of relevance is defined, but it has been argued (Walton, 2004) that an argument should be judged to be relevant in a case only if it is part of a connected sequence of argumentation used in a dialog leading to an ultimate probandum to be proved in that case. In a particular case, whether an argument is judged to be relevant or not depends on how far the sequence has gone forward at the stage where it was put forward. Such matters need to be judged by examining the text of discourse in the given case being analyzed, and asking what the purpose of the discourse is supposed to be. Some cases can be difficult to decide, because the argument simply is not finished yet, or even if it is finished, because there are a lot of gaps and missing premises, and it may not even be clear what type of dialog the participants are supposedly engaged in. however in the case is being considered here, the key indicator of irrelevance is that of the dialectical shift.

The issue of the case was whether the United States had justice on its side in waging the Mexican war of 1848. Presumably the type of dialog here was some sort of persuasion dialog on which country had justice on its side in that war. This issue is a historical question, or perhaps an ethical question, of a kind commonly disputed by historians, or by anyone interested in this kind of issue. The arguer goes on to claim that questioning the initial claim is unpatriotic, and would give comfort to our enemies. This argument from negative consequences seems like a reasonable one if considered as part of a deliberation dialog. Perhaps raising this question might indeed give comfort to our enemies, as the claim states. But the question is whether this claim is relevant to the original issue being discussed. Using the second (dialectical) level of analysis it can be argued that it is not, because there has been a dialectical shift to prudential questions concerning the consequences of discussing the original issue of whether the United States had justice on its side in the Mexican war. This kind of case is quite common one, and all comparable examples presumably share this bi-level underlying structure. For example comparable arguments commonly occur in cases of freedom of speech. 


\section{Discussion of the other examples}

The riots example is interesting because there is clear evidence of a dialectical shift. The issue in the case is supposed to be that of whether the defendant should be acquitted of the crime he was charged with. This is an issue to be decided by a trial in which evidence for and against the charge is considered and evaluated by a judge or jury. Acquitting the defendant for the practical reason that there will be riots in the streets, while being in principle a reasonable argument from negative consequences, is not relevant to the conclusion that the defendant should be found guilty as the outcome of the trial. This argument is a clear instance of an inappropriate use of public pressure, in the form of argument from negative consequences, brought to bear on a trial in the judicial system. When the argument is shown in this light, it is quite clear that there has been a dialectical shift from a persuasion type of dialogue to a prudential argument about matters of public safety, or damage caused by riots. This argument is very similar to the Mexican war argument, and is fallacious for much the same reasons.

The drinking example is also interesting because, at least on the surface, it seems to be a highly reasonable argument directed to the respondent to support the conclusion that he should stop drinking. The reason given is that continuing this action may make him die young, like his father. However, we can critically question premises and implicit assumptions in the argument. Did his father really die young, and if so was it because of his drinking? How similar is the case of the father to that of the son? Maybe there was some difference, for example, in how each individual reacted to alcohol, or in how much alcohol each one was drinking. But failure to substantiate a premise of an argument, whether explicit or implicit, should not be sufficient reason to judge it fallacious. Here we have a prudential argument that does present a reason for the conclusion, based on alleged negative consequences. It is not a fallacious argument from consequences.

In the free will example, even though the dialectical shift is implicit, the illegitimate nature of the move in argumentation is obvious to everybody. It is seen as shockingly inappropriate. It meets the general requirements for the speech act of making a threat as a move in dialog (Walton, 2000). The proponent of the threat warns the respondent that something that negative consequences may happen to him. The proponent also indicates to the respondent that she (the proponent) will see to it that these negative consequences come about, unless the respondent complies by carrying out (or omitting to carry out) some designated action. In the analysis of (Walton, 2000, 113-114), there are three essential conditions for the speech act of making a threat.

- The preparatory condition states that the respondent believes that the proponent can bring about the negative consequences. 
- The sincerity condition states that both the proponent and the respondent presume that the respondent wants to avoid the negative consequences.

- The essential condition states that the proponent is making a commitment to bring about the negative consequences if the respondent does not comply.

In the free will example, the threat is an explicit one, and it is clear to everyone that it is inappropriate in relation to the critical discussion that the professor and student are supposed to be engaging in. In contrast, in the firebombing example, the "insurance salesman" is making an indirect threat. An indirect threat is meant to be recognizable to the respondent as a threat, but is also an implicit speech act that leaves room open for plausible deniability.

An interesting aspect of the free will example is its contextual sensitivity. Changes to the circumstances of the example could make what was formerly an outrageously irrelevant argument into a perfectly good argument. Consider the following two modifications of the original circumstances of this example. ${ }^{6}$ First, suppose that the student's argument was based on racist or other pernicious views. In this kind of case the position adopted by the student is itself unacceptable, and therefore the professor could be justified in telling the student that if he continues to maintain this unacceptable view, he will fail the course. Second, suppose the position advocated by the student showed a misunderstanding of the material in the course. For example, suppose the student had put forward an argument that had already been rejected in the course as untenable because it had been shown to be based on a false assumption, like $2+2=5$. Similarly, in this kind of case the professor could be justified in telling the student that he will fail the course if he continues to maintain this unacceptable view. The interesting aspect brought out by consideration of these two kinds of examples is that this threat argument that was previously fallacious now has become a non-fallacious argument. It shows that an argument that is clearly a fallacious instance of argumentation from negative consequences can be turned into a reasonable argument provided only that the circumstances of the case are slightly different.

Another interesting aspect of the free will example is that there appears to be a shift to a different level of dialog when the professor puts forward his counterargument to the student. The student began, in the discussion of the issue of free will versus determinism, by putting forward an argument for determinism. The professor, at his next move, does not put forward an opposing argument for free will, nor does he criticize the student's argument for determinism, at least directly. Instead, he makes a remark about the students advocating the argument for determinism, by giving a reason why the student should stop advocating that argument. This move by the professor can be seen as a dialectical shift to a meta-dialog. If the original persuasion dialog about the free will issue can be called a ground level dialogue, then a meta-

\footnotetext{
${ }^{6}$ These two modifications of the free will example, and their implications, were expressed in comments made by Trevor Bench-Capon on February 13, 2008, during a talk at the University of Groningen.
} 
dialog could be defined as a dialog about that original dialog (Krabbe, 2003, p. 83). In this instance, when the professor puts forward his argument telling the student that he had better stop advocating determinism or he will get a failing grade, there has been a shift to a meta-dialog. The reason is that the professor is now discussing the original dialog, a persuasion dialog, and telling the student to stop it, or at least stop his part in it that consists of giving arguments for determinism. He is telling the student to either stop it, or he will give him a failing grade in the course. This observation would also apply to the Mexican war example.

As noted in the discussion above of the jury intimidation example, here we have a prudential threat appeal argument used to intimidate somebody into taking a course of action, but nobody is being deceived by it. Or let's say, at any rate, to make the example interesting, that the jury member is not deceived by the threat, but simply acts in accord with it for prudential reasons, because he fears for his life. In such a case, although the ad baculum argument was clearly irrelevant to the discussion, it did not fool anybody into thinking it was a relevant argument. In such cases, the ad baculum could still have quite an effect by inhibiting the respondent. In such a case, the ad baculum strategy may work as a fallacy, even when there is no deception that it is relevant. Thus deception is not the only basis for judging an ad baculum argument to be fallacious. In some cases, the respondent is quite aware that the threat appeal is irrelevant, but gives in to it anyway on the basis of self-interest.

But has the motorcycle gang, the jury member, or anyone else, really committed a fallacy? You could argue not, on the ground that a fallacy always requires deception, and all parties might clearly recognize that the tactic used is wrong. Nobody is being deceived. But the gang might use the argument anyway, and the jury member might be persuaded to act in accord with it anyway. In this kind of case, the fallacy could result from a dialectical shift from one setting in which an argument was used to a different setting. It could be prudentially justified for the jury member to respond to the threat, but in the setting of the trial, the threat is not relevant evidence, or should not be treated as such. It should not influence the jury member to decide whether the accused party is guilty or not. As in the other examples, the burden of persuasion in the trial is not met by the purely prudential argument directed against the juror.

On the surface, the argumentation in the jury intimidation example looks very similar to that in the case of the riots example. There is a trial involved, but the argument shifts to prudential concerns by using argument from negative consequences. We do want to say in the jury intimidation example that something is wrong. It is improper that a jury member should be intimidated, and in fact this type of act is illegal, on grounds of obstruction of justice, the reason being that it makes a fair trial difficult or impossible. So the tactics used by the motorcycle gang are certainly illegal, as well as being unethical. But do they commit a fallacy? There could be some grounds for saying so, because they are shifting the argument from the kind of critical discussion based on evidence used in a trial to purely pragmatic matters of safety because a person fears for his life. Although it is possible that nobody is being deceived by this 


\section{Douglas Walton}

move, still there could be grounds for classifying the argument as a fallacious ad baculum, or use of a threat. These grounds would be that of relevance. As stated in the jury intimidation example, the threat to kill the jury member is irrelevant as legal evidence that should be considered in the trial. On these grounds, a case could be made that a fallacious ad baculum argument is committed in this example.

Still, if this evaluation is correct, it takes us back to the riots argument, where there was a similar dialectical shift from a trial to a prudential argument based on negative consequences. On these grounds, the riots argument could perhaps also be judged to be an instance of a fallacious ad baculum argument. The grounds are that the possibility or probability of riots should not be taken to be a good or adequate reason to support the conclusion that the defendant should be found guilty. It is irrelevant, even though it may be relevant to drawing other conclusions as prudential courses of action, like shifting the venue of the trial to a different location, or rescheduling the time of the trial.

What makes the argument in the domestic insurgency example most interesting, and different from the other examples, is the added element that a kind of practical inconsistency is alleged. It is argued that the liberals that are the target of the argument have certain values, like gender equality, that the terrorists are opposed to. But then it is argued that their attempts to promote these values and impose them on the rest of the world are actually undermining the same values by promoting the interests of the terrorists. Thus it is alleged that the consequences of the liberals' attempts to promote their position and values are in fact undermining them. This argument against the liberals accuses them of being committed to a pragmatic inconsistency of the same kind we are already familiar with in circumstantial ad hominem arguments. Thus the argument in this example is certainly an interesting and subtle one as an attack, but is it fallacious?

In the domestic insurgency example there has been a dialectical shift from a discussion about ethical values to a citing of alleged negative consequences of the expression and promotion of these values by certain parties. Thus it seems similar to the Mexican war example as an instance of argument from negative consequences. However, the argument in the domestic insurgency example is more subtle and indirect than that of the Mexican war example. D'Sousa did argue at length that the political activism of the persons and groups cited had bad negative consequences. He did not argue that that these people have no right to express their views or to promote them politically, however. But, like the case of the Mexican war example, it was argued that the bad consequences involve loss of life. In the Mexican war example, loss of morale in war was cited as the bad outcome-giving comfort to our enemies. In the domestic insurgency example, the consequences cited are even worse. The argument equates the bad consequences with loss of life in terrorist attacks, and even appears to partially lay blame for these attacks on the parties cited. Thus there is a dialectical shift from a discussion of the political views in question to a deliberation dialog about the allegedly bad consequences of these views. The secondary dialog even takes the form of laying guilt for 
these bad consequences on the parties who are alleged to have contributed to them, even if unknowingly.

The argumentation in this case is much more complex than the one in the Mexican war example, because it was put forward in a whole book, and because of its politically divisive nature. Those on the right will like the argument in the book, while those on the left will be strongly inclined to disagree with its argument. But it would be an error to leap too quickly to one side or the other. To properly evaluate the argument, one would have to examine the specific claims made in the individual cases cited, and the arguments offered to back up these claims. There is no space for that here. Still, it is interesting to cite the example to show how argumentation from negative consequences is used in everyday conversational arguments of the most common kind, for example in political rhetoric, in a subtle way. Such cases verge on the fallacious, because of the shift concealed within the sequence of argumentation, and can certainly be highly deceptive. But it would be erroneous to declare them fallacious in a wholesale fashion, and each case needs to be judged on its merits or demerits, taking the dialectical shift into account.

\section{Retrospective evaluation}

The remaining problem is how one should approach a particular case, like the examples presented in section 1, where it appears evident to a reader or viewer of the example that argument from consequences may be involved. The initial piece of advice would be to look to see if the argument has the wrong conclusion. But how could one be expected to know or to prove that it has the right conclusion or the wrong conclusion? The next required step is to make some determination of what type of dialog the argument is supposed to be contributing to. For example, there may be evidence that the argument was supposed to originally take place in the context of a persuasion dialog. Yet a problem may arise if there is also evidence that the argument has been put forward in such a way that it can only be reasonable if it is taken to be part of some other type of dialog like a deliberation dialog. What these observations suggest is that the ordering of the two dialogs is crucial. We have to approach the case by identifying dialog type $x$ that the argument appears to part of, and then analyze the whole sequence of argumentation in the case retrospectively, tracing back to dialog type $y$ at an earlier point in the sequence.

Analyzing the Mexican war example needs to take a retrospective approach, an approach based on the assumption that there has been a dialectical shift from one type of dialog to another. The alleged shift is from a persuasion dialog on an issue to a different type of dialog, a prudential type of deliberation dialog. The case is similar to many threat appeal and fear appeal arguments where the argument may be reasonable, when considered in itself, but becomes fallacious when considered in the context of dialog. Consideration of the context may indicate there has been a dialectical shift, and that this shift is 


\section{Douglas Walton}

evidence of the committing of a fallacy. However, one problem in this case is how we can be sure the original issue was supposed to be part of a critical discussion. There is very little evidence in the case. There are no indicator words or other textual evidence to show that to participants were originally engaged in a critical discussion on the issue of which country had justice on its side in the Mexican war of 1848 . The only evidence is that the first statement in the Mexican war argument is put forward as an assertion. The statement is made that the United States had justice on its side in waging the Mexican war of 1848. The statement appears to be a claim made by one party in a dispute, because the second statement in the Mexican war argument appears to respond to it by giving a reason against questioning it. When the first statement is made therefore, it would appear that there is a burden of persuasion set on the party who made the claim, because presumably it is a claim being made to attempt to overcome the doubt of some other party in the dialog. But the requirement of lifting this burden was not met, because of the shift to the second type of dialog.

The structure of this kind of shift is illustrated in Figure 3 below.

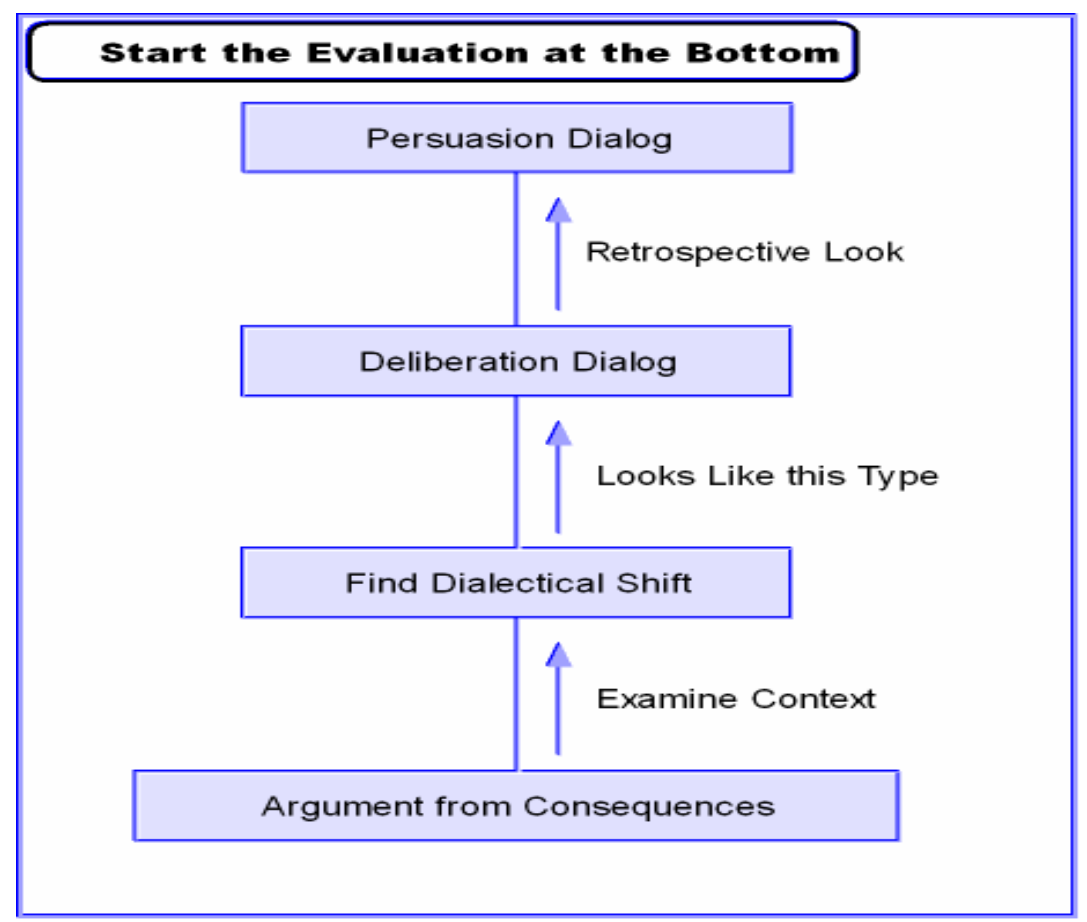

Figure 3: Retrospective Evaluation of Argumentation from Consequences

Figure 3 portrays the progress of a sequence of argumentation from a given argument in an example that has been identified as fitting the scheme for argument from consequences. But when we evaluate how this argument has been used in the example retrospectively, we need to trace it back to the original persuasion dialog it was supposedly part of. To critically analyze an ad baculum argument used in such a case, or other type of argument coming under 
the heading of argument from consequences, we have to adopt a backwards or retrospective viewpoint, starting with the bottom box in Figure 3. From the bottom box, where the argument was put forward in the example, we need to look backwards to the original rules of the persuasion dialog. From this perspective, the argument can be judged to be fallacious if there was an illicit shift from the original persuasion dialog represented in the top box to another type of dialog represented beneath it. Thus looking backwards we can reconsider the argument in its original context of dialog, and judge it to be irrelevant if the text and context of the argument supports that interpretation of the example. This methodology is called a retrospective analysis of the argumentation, as shown in Figure 3.

The point was made in (Walton and Krabbe, 1995, p. 104) that shifts from persuasion dialog to another type of dialog are not always fallacious, but that the shift is fallacious, or can be associated with a fallacy, when it is a shift of an illicit or inappropriate type. In a case cited there (p. 104), a minister of finance argued for a certain kind of tax exemption, and he went on to propose that if his critics would abstain from moving for penalties for these exemptions, he will refrain from opposing a bill that these critics would profit from. In this case, the minister evaded the issue by illicitly abandoning the original persuasion dialog and moving to a negotiation dialogue. The shift is illicit because the negotiation dialog does not support the original persuasion dialog, but moves away from it leaving it unfinished, and perhaps even preventing it from continuing in a more productive manner towards its goal. It is this kind of shift, as shown by the examples above, that is characteristic of many instances of fallacious argumentation from consequences, including the ad baculum fallacy.

In the system of formal persuasion dialog set out by Wells and Reed $(2006,7)$ a shift to a different type of dialogue, like a negotiation dialogue, can take place only if the party making the shift has requested this sort of move to the other party. They also make it a rule of their formal persuasion dialog that a progression to another type of dialog is only allowed if the party requesting the shift first provides the defense of his thesis. In their system, a shift is only licit after the party requesting the shift has first discharged the burden of proof to support his previous argument in the persuasion dialog. These requirements are put in place because a shift is held by Wells and Reed to be useful in a persuasion dialog only if one party is getting nowhere with trying to persuade the other party, with appropriate arguments that supports his thesis. If the persuasion dialog is failing because of a deadlock, where one party simply cannot go further to persuade the other, that is the appropriate kind of situation where a shift to a negotiation might prove to be useful. They see the rules of their system of persuasion dialog as blocking the inappropriate type of dialectical shift, where the party making the shift is using the argument in a secondary dialog to fallaciously fulfill a burden of proof required for a prior argument put forward in the primary dialog.

How can we support the hypothesis that we should interpret the text of discourse in cases like of the Mexican war argument in such a way that it 
shows evidence of an illicit dialectical shift? The invocation of the normative model of the critical discussion, by itself, is insufficient as a basis for such an interpretation. In addition, what is required is an analysis of the text to back up the hypotheses that this normative model fits the argumentation in this case and that there has been a shift from this prior dialog to a deliberation dialog. On this view of the matter, when we examine the text of discourse, we can see that the argumentation in the case fits a certain type of dialog, in this case a kind of historical discussion about values of the familiar kind. Since all of us as participants in everyday conversational argumentation can recognize this type of dialog, we can then fit it into a normative model like that of the critical discussion. As shown above, just before Figure 3, the evidence is that the first statement in the Mexican war argument (that the United States had justice on its side in waging the Mexican war of 1848) is put forward as a claim made by one party in the dialog. When this statement is made, a burden of proof is set on the party who made it. When this claim is in question by the other party, the burden needs to be lifted by the claimant, and that is how the persuasion dialog needs to properly proceed. However, the shift to the second type of dialog, put in place by the reason the claimant gave to support his claim, interfered with the proper continuation of the dialog by taking it in a different direction. The requirement of lifting this burden was therefore avoided, or at least that was the sophistical strategy used to try to avoid meeting the requirement at the next step in the persuasion dialog.

The dialectical structure of this kind of fallacious argumentation is displayed in Figure 4.

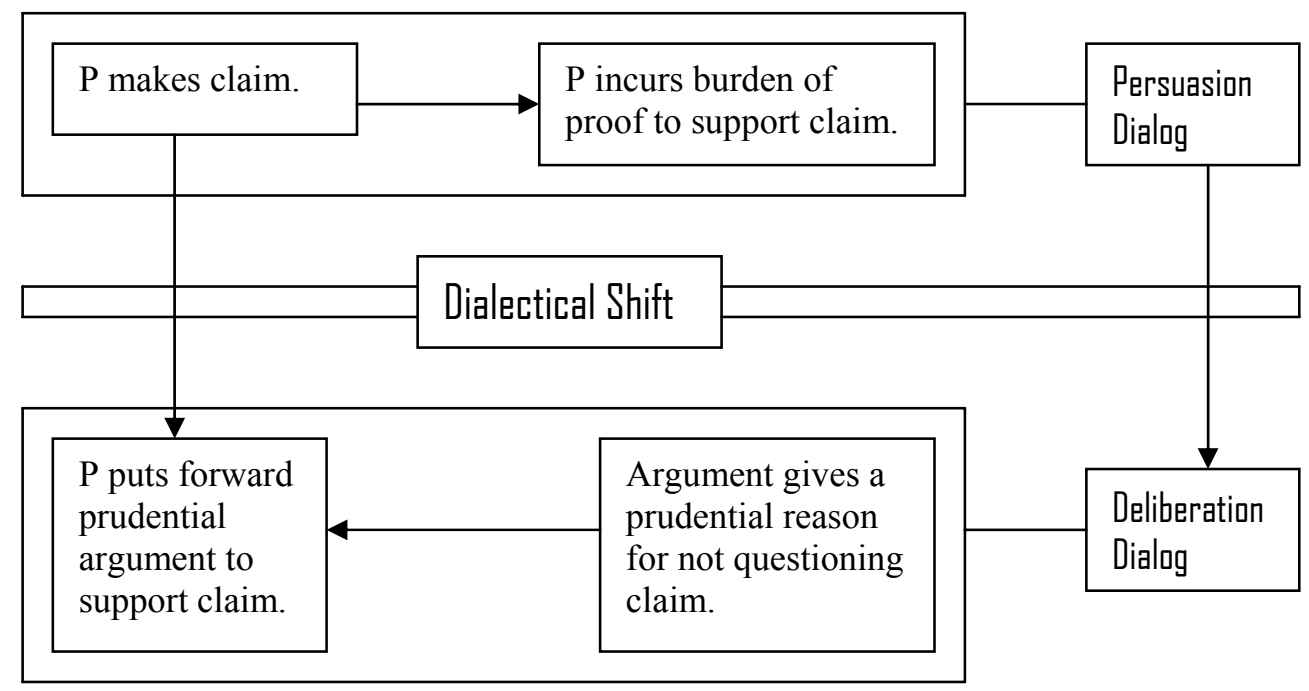

Figure 4: Dialectical Structure Underlying Shifting from Burden of Proof

The fallacy is a failure to lift a burden of persuasion that was set in place against the proponent when he made a claim in the original persuasion 
dialog. Such a failure is not in itself fallacious, but the problem was that, at his next move, the proponent offered a prudential argument for the respondent to accept the claim he had just made. The offering of such a prudential argument did give the respondent a practical reason not to dispute or question the claim, but unfortunately it only functions in this way if there is a shift to a deliberation dialog. The problem is that proponent is shifting away from fulfilling the requirement of burden of proof in the persuasion dialog by presenting a kind of argument that moves to a deliberation dialog. This move interferes with the progress of the persuasion dialog, because it cannot move forward towards realizing its goal until the proponent either backs up his claim by giving evidence that it true or withdraws it.

\section{Conclusions}

The examples studied suggest that evaluation of cases of supposed informal fallacies needs to be carried out both by identifying the type of argument that is involved, and by examining how that argument is used in the context of dialog. This way of proceeding is supported by the theory of fallacy in (Walton 1995, 255). People generally recognize kinds of arguments that are typically reasonable (in principle) but defeasible, and best seen as heuristics to guide action under conditions of uncertainty even though they are subject to failure in some instances. People also recognize that these kinds of arguments can be used very effectively as deceptive tactics, and thus they are on their guard against them if they see any evidence at all of exaggeration or sophistical maneuvering. These arguments have two sides. They are necessary and useful, but at the same time slippery and dangerous. When it comes to evaluating such arguments, instead of routinely dismissing them as fallacious, we need to realize that they can fall into one of three standard categories: (a) reasonable, when considered in the context of dialog; (b) weak but not fallacious; (c) fallacious. To take a given argument in a real case, like the examples considered above, and to marshal the textual evidence to justify placing them in one of these categories, attention should be paid both to the form of reasoning and to the appropriateness of using this reasoning in the context of dialog for the given case.

On this approach, a fallacy is an argumentative move that goes counter to the direction of a dialog and poses an obstacle to the realization of the goal of the dialog it is supposed to contribute to. An instance is the group of fallacies associated with dialectical shifts.

The evaluation of arguments from consequences depends not only on the logical form of the argument, abstracted from its context, but also on the dialectical context of how the argument was used for some purpose in a dialog setting. The very same argument that was appropriate and reasonable when used as part of a deliberation dialog can be irrelevant, and for this reason fallacious, when used in a persuasion dialog. Such arguments need to be evaluated using a retrospective model in which one looks backwards to identify 
the original type of dialog that the argumentation was supposed to be a contribution to. It is from the viewpoint of this original type of dialog that the argument should be evaluated, according to the methodology presented above. Using the formal model of Wells and Reed (2006), we have to ask whether the rules specifying requirements for starting a new sub-dialog have been met. Only if these rules are followed can the shift properly be made from the initial dialog that was already under way to a new sub-dialog. Only then can there be a clean and visible progression from the one type of dialog to the other. The problem, however, in the cases we have examined, is that in an ordinary conversational argument, the underlying shift may be invisible. It lies under the surface of the text, and the participants are quite likely not even to be aware of its occurrence.

In this paper eight structural characteristics help to explain how the argument in the Mexican war example, and other cases studied, can be identified as a fallacious use of argument from consequences. First, there was a dialectical shift from a persuasion dialog to a deliberation dialog. Second, when we evaluate the argument in the deliberation dialog retrospectively, by looking back to the rules and requirements of the original persuasion dialog, we can see that the deliberation dialog is not helping the original persuasion dialog move forward towards realizing its goal of resolving the original conflict of opinions. Third, there was no agreement made between the parties that the shift to the second type of dialog was acceptable to both. Fourth, no rule that allows such a shift from the first dialog the argument was cited or met. Fifth, the argument put forward in the deliberation dialog has a different conclusion from the one that the arguer was originally supposed to prove in the persuasion dialog. It is the wrong conclusion. Sixth, there was a shift to a metadialog, visible in the contrast between conclusions $\mathrm{A}$ and $\mathrm{A}+$ in the two argument diagrams for the Mexican war example (Figures 1 and 2). Proposition A+ is about questioning proposition A in public. Seventh, the argument put forward in the deliberation dialog does not fulfill the requirements for burden of persuasion. Eighth, a structural characteristic that holds for the examples studied in this paper is that the shift is specifically from a persuasion dialog to a deliberation dialog. Whether this characteristic holds for all examples of fallacious use of argument from negative consequences is merely a hypothesis, however, and remains to be studied in future work.

The analysis of the structural characteristics of the argumentation in these relatively simple examples puts us in a position to analyze much more complex and subtle cases. These cases are common, controversial and interesting. They typically involve arguments citing the negative consequences of artistic or political communication. For example, the film Clockwork Orange, and many other films and literary works as well, have been criticized on the grounds that they tend to promote violence. Indeed, murderers have sometimes admitted that their violent acts were inspired by books or movies. It may be true in some instances that these works of art have had unfortunate consequences. But is that the basis of a good argument for condemning them? It might be, in some respects, but one has to be careful not to commit the fallacy of improper argument from consequences. For such a work of art may have literary or 
artistic merit, even though it did have the bad consequences cited. Still, from a prudential or deliberative point of view, the argument may have some worth, provided it is not directed to condemning the work as bad art, but rather to arguing for restricting its communication to a public audience on grounds of danger to life. Classic cases of freedom of speech typically tread on the borderline of this kind of fallacy.

The examples studied in this paper reveal that arguments from consequences are often reasonable in shifting the burden of proof under conditions of uncertainty and lack of knowledge. But these examples also show that such arguments are often dangerous in that they have a powerful persuasive effect that goes far beyond the force of rational persuasion that they should be properly taken to carry. The question is how they work as rhetorical strategies of strategic maneuvering (van Eemeren and Houtlosser, 2000). It may be suggested as a hypothesis, based on what has been shown, that the reason for this deceptiveness is that failures of relevance associated with these kinds of fallacies are concealed by dialectical shifts. According to this hypothesis, rhetorical persuasiveness of these arguments depends on concealed dialectical shifts that need to be brought out by analysis of cases, which show how criteria that need to be used to judge such arguments fallacious or not in specific cases must take such dialectical shifts into account.

One problem with all the examples studied in this paper is that they are short, and appear to be quite simple on the surface, but once a critic attempts to analyze the example, it is found that there is a lot of implicit communication under the surface. All of the examples can be analyzed at two levels. At the inferential level, the fallacy of argumentum ad consequentiam can straightforwardly be identified as one of wrong conclusion. But to pinpoint in depth what is wrong, to teach students to properly identify and analyze the fallacy in such cases, and to grasp rhetorically how such arguments can be powerfully deceptive, one needs to proceed to the dialectical level. One needs to ask what conclusion the given argument actually does support. A problem exposed here is that the given argument may fit the argumentation scheme for value-based practical reasoning, and thereby give the respondent a reason for taking action or not. Looked at in this way, the argument seems reasonable, and indeed it may be a reasonable, provided the dialectical shift is not taken into account, and the prudential conclusion is taken as the real one to be proved. Once the shift is taken into account, the diagnosis of the failure is that meeting the requirement of fulfilling the burden of persuasion has not been met by the prudential argument that has been put forward.

\section{Acknowledgements}

The author would like to thank the Social Sciences and Humanities Research Council of Canada for a research grant that helped to support the work in this paper. An earlier version of the paper was read on February 14, 2007 as a keynote address at the International Conference on Strategies of 
Argumentation held at the University of Groningen, held in conjunction Erik Krabbe's Valedictory Lecture. I would like to thank Trevor Bench-Capon, Erik Krabbe, Henry Prakken and Bart Verheij for especially useful questions and comments on this earlier version.

\section{References}

Aristotle (1937). The Art of Rhetoric. Trans. John Henry Freese. Loeb Classical Library. Cambridge, MA: Harvard University Press. I

Atkinson, Katie, Trevor J. M. Bench-Capon and Peter McBurney (2006). Computational Representation of Practical Argument. Synthese 152, 157206.

Bench-Capon, Trevor J. M. (2003). Persuasion in Practical Argument Using Value-based Argumentation Frameworks. Journal of Logic and Computation 13, 429-448.

Eemeren Frans H. van and Rob Grootendorst (2004). A Systematic Theory of Argumentation. Cambridge: Cambridge University Press.

Eemeren, Frans H. van and Peter Houtlosser (2000) Strategic Maneuvering in Argumentative Discourse: a Delicate Balance. In Frans H. van Eemeren and Peter Houtlosser (eds), Dialectic and Rhetoric: the Warp and Woof of Argumentation Analysis. Dordrecht: Kluwer, 131-159.

Guerini, Marco and Cristiano Castelfranchi (2006). Promises and Threats in Persuasion. 6th Workshop on Computational Models of Natural Argument (CMNA 6). European Conference on Artificial Intelligence (ECAI 06). Riva del Garda, Italy: August 28.

Jacobs Scott and Sally Jackson (2006). Derailments of Argumentation. In Peter Houtlosser and Agnes van Rees (eds), Considering Pragma-Dialectics. Mahwah, NJ: Erlbaum, 121-133.

Krabbe, Erik C. W. (2003). Metadialogues. In Frans H. van Eemeren, J.Anthony Blair, Charles A. Willard and A.Francisca Snoek Henkemans (eds), Anyone Who Has a View: Theoretical Contributions to the Study of Argumentation. Dordrecht: Kluwer, 83-90.

McBurney, Peter, David Hitchcock and Simon Parsons (2007). The Eightfold Way of Deliberation Dialogue. International Journal of Intelligent Systems 22, 95-132.

Nicoloff, Franck (1989). Threats and Illocutions'. Journal of Pragmatics, 13, 501-522.

Prakken, Henry (2006). Formal Systems for Persuasion Dialogue. The Knowledge Engineering Review, 21, 163-188.

Rescher, Nicholas (1964). Introduction to Logic. New York: St. Martin's Press.

Walton, Douglas (1995). A Pragmatic Theory of Fallacy. Tuscaloosa, AB: University of Alabama Press.

Walton, Douglas (1996). Argumentation Schemes for Presumptive Reasoning. Mahwah, NJ: Erlbaum.

Walton, Douglas (2004). Relevance in Argumentation. Mahwah, NJ: Erlbaum. 
Walton, Douglas Scare Tactics: Arguments that Appeal to Fear and Threats. Dordrecht: Kluwer.

Walton, Douglas (2006). How to Make and Defend a Proposal in Deliberation Dialogue. Artificial Intelligence and Law, 14, 177-239.

Walton, Douglas and Erik C. W. Krabbe (1995). Commitment in Dialogue. Albany: State University of New York Press.

Walton, Douglas, Chris Reed and Fabrizio Macagno (2008). Argumentation Schemes. Cambridge: Cambridge University Press.

Wells, Simon and Chris Reed (2006). Knowing when to Bargain: the Roles of Negotiation and Persuasion in Dialogue. 6th Workshop on Computational Models of Natural Argument (CMNA 6). European Conference on Artificial Intelligence (ECAI 06), Riva del Garda, Italy, August 28. 